"La educación es un derecho, no un privilegio": la lucha estudiantil contra el arancel universitario durante la última dictadura en Argentina (1980-1983) Guadalupe Seia

páginas / año 12 - n 30 Septiembre-Diciembre / ISSN 1851-992X/ 2020

http://revistapaginas.unr.edu.ar/index.php/RevPaginas

DOI: http://dx.doi.org/10.35305/rp.v12i30.450

\title{
"La educación es un derecho, no un privilegio": la lucha estudiantil contra el arancel universitario durante la última dictadura en Argentina (1980-1983) ${ }^{1}$
}

\author{
"Education is a right, not a privilege": the student struggle against \\ university fees during the last dictatorship in Argentina (1980-1983)
}

\author{
Guadalupe Seia \\ Universidad de Buenos Aires; \\ Instituto de Altos Estudios Sociales; \\ Universidad Nacional de San Martín; \\ Consejo Nacional de Investigaciones Científicas y Técnicas (Argentina) \\ guadalupeseia@gmail.com
}

\section{Resumen}

La dictadura del autodenominado "Proceso de Reorganización Nacional" (1976-1983) buscó imponer un modelo universitario abiertamente anti-reformista y excluyente, eliminando la autonomía y el co-gobierno universitario, imponiendo cupos y aranceles para el acceso y la permanencia del estudiantado. En este artículo analizamos la oposición estudiantil al arancelamiento del cursado de las carreras de grado en la Universidad de Buenos Aires a partir de 1980, luego de la sanción de la Ley Universitaria.

Sostenemos que la reivindicación contra el arancel fue fundamental para potenciar la reorganización estudiantil en el marco de la última dictadura. Asimismo, argumentamos la relevancia de la movilización estudiantil para revertir el modelo universitario de la dictadura y para la construcción de los principios fundamentales de la universidad democrática. En ese sentido, este texto se propone como un aporte a la historización de la conquista de la educación superior pública y gratuita como un derecho humano.

\section{Palabras clave}

Movimiento Estudiantil; Arancel; Gratuidad; Universidad; Dictadura.

\section{Abstract}

The dictatorship of the "National Reorganization Process" (1976-1983) sought to impose an openly anti-reformist and exclusive university model, eliminating university autonomy and co-government, imposing quotas and fees for student access and permanence. In this article we analyze the student opposition to the fees on high education at the University of Buenos Aires since 1980, after the sanction of the new university law.

We maintain that the claim against the fees was fundamental to enhance student reorganization under the last dictatorship. Likewise, we argue the relevance of student mobilization to reverse the university model of the dictatorship and to the construction of

\footnotetext{
${ }^{1}$ El presente artículo se basa en la investigación desarrollada para nuestras tesis doctoral (2019) y consiste en una re-elaboración crítica y ampliada de la ponencia "La resistencia contra el arancelamiento en la Universidad de Buenos Aires (UBA) durante la última dictadura (1976-1983)" presentada en las VI Jornadas de Estudio y Reflexión sobre Movimiento Estudiantil Argentino y Latinoamericano, desarrolladas en el Instituto de Investigaciones Gino Germani en 2016.
}

Esta obra está sujeta a la Licencia Reconocimiento-NoComercial-CompartirIgual 4.0 Internacional de Creative Commons. http://creativecommons.org/licenses/by-nc-sa/4.0/ 


\section{Guadalupe Seia}

the fundamental principles of the democratic university. In that sense, this text is proposed as a contribution to the historicization of the conquest of public and free higher education as a human right.

\section{Keywords \\ Student Movement; Fees; Tuition Free; University; Dictatorship Introducción ${ }^{2}$}

A cien años de la Reforma Universitaria y setenta de la declaración de la gratuidad universitaria ${ }^{3}$, el acceso a la educación superior concentra actualmente la atención de cientistas sociales y también autoridades educativas. En el presente artículo, nos ocupamos de una etapa histórica en que se buscó erradicar ambas conquistas del modelo universitario argentino. La dictadura del autodenominado "Proceso de Reorganización Nacional" (1976-1983) buscó imponer un modelo universitario abiertamente anti-reformista y excluyente eliminando la autonomía y el cogobierno universitario, re-imponiendo cupos y aranceles para el acceso y la permanencia del estudiantado.

Nos concentramos en la oposición estudiantil al arancelamiento del cursado de las carreras de grado en la Universidad de Buenos Aires a partir de 1980, luego de la sanción de la Ley Universitaria. Con el análisis de la militancia estudiantil contra el arancelamiento, nos proponemos colaborar a revertir una vacancia existente en la historización de la gratuidad universitaria. Hasta el momento han primado miradas centradas en los cambios en el marco legal que dispuso cambios para afirmar o revertir la gratuidad de la educación superior en Argentina (Rodríguez, 2015); el significado de esta medida en el proyecto universitario y de país de los diferentes gobiernos que concretaron esas políticas (Benente, 2019); o bien sobre los efectos que la disposición de la eliminación o la imposición de aranceles tuvo sobre el sistema universitario (Buchbinder y Marquina, 2008; Seia, 2018a; Friedemann, 2019).

Existen escasos trabajos que incorporan en su abordaje un análisis de los posicionamientos del movimiento estudiantil sobre las disposiciones relativas a la gratuidad durante los gobiernos peronistas (Pis Diez, 2019; Friedemann, 2019), en contraste con los estudios sobre las movilizaciones estudiantiles contra el denominado "limitacionismo" durante la primera mitad de la década de 1970 bajo la dictadura autodenominada como "Revolución Argentina"4 (Bonavena y Millán, 2008; Seia, 2014; Califa y Seia, 2017). En esta última línea interpretativa se ha destacado la importancia de la movilización estudiantil para revertir las medidas restrictivas del acceso y la permanencia en las universidades nacionales. Esta

\footnotetext{
2 Agradecemos las observaciones y sugerencias realizadas por las/los evaluadores del manuscrito. Las interpretaciones aquí propuestas corren exclusivamente por nuestra cuenta.

${ }^{3}$ El desarancelamiento de los estudios universitarios se estableció mediante el Decreto $\mathrm{N}^{\circ} 29.337$ del 22 de noviembre de 1949 (Benente, 2019).

${ }^{4}$ Durante esa etapa, la gratuidad de los estudios de grado estaba sujeta a una serie de condiciones de regularidad y méritos académicos (Pis Diez, 2019). Las restricciones más importantes pasaron por la imposición de cupos al acceso (Califa y Seia, 2017).
} 


\section{"La educación es un derecho, no un privilegio": la lucha estudiantil contra el arancel universitario durante la última dictadura en Argentina (1980- 1983)}

hipótesis, que ha sido poco explorada para otras etapas históricas, es retomada en este artículo para el estudio de los años de la última dictadura en Argentina.

En este artículo argumentamos la relevancia de la movilización estudiantil contra el arancel durante la última dictadura en dos sentidos fundamentales. En primer lugar, sostenemos que dicha reivindicación potenció la actividad del movimiento estudiantil de la UBA que venía re-articulando su organización desde los meses posteriores al golpe de estado de 1976, así como también posibilitó la construcción de un discurso crecientemente crítico hacia el modelo de universidad propuesto por la dictadura. En segundo lugar, afirmamos que la movilización estudiantil contra el arancel, en particular, y las limitaciones en el acceso y la permanencia, en general, fueron piezas claves para la construcción de una agenda universitaria y de un modelo de universidad de la democracia.

En las páginas siguientes describimos la agencia estudiantil como parte de la oposición a la dictadura en la universidad y también de la construcción de la universidad democrática, discutiendo aquellas afirmaciones que describieron la "muerte" del movimiento estudiantil a partir de la dictadura en Argentina (Vila, 1985; Brunner, 1985). ${ }^{5}$ En ese sentido, este texto se propone como un aporte más a la historización de la conquista de la educación superior como un derecho humano (CRES, 2018; Benente, 2019).

Este texto constituye un fragmento de nuestra tesis doctoral acerca de las reconfiguraciones del movimiento estudiantil de la UBA durante la última dictadura. Es producto de un trabajo de triangulación intermetodológica por el que analizamos complementariamente diferentes tipos de fuentes. Por un lado, material estadístico procesado por diferentes reparticiones universitarias y educativas, junto a datos brindados en la prensa periódica de la etapa y sistematizados por nosotros. Por otro lado, el análisis cualitativo se basa en la sistematización de fuentes documentales heterogéneas como publicaciones juveniles de los partidos políticos de izquierda, centros de estudiantes y federaciones, la prensa nacional, normativa universitaria y educativa, etc. y también fuentes orales constituidas por testimonios de estudiantes de la UBA con y sin militancia durante los años de la dictadura. ${ }^{6}$ Por último, también

\footnotetext{
${ }^{5}$ Vila (1985) sostuvo que el rock nacional se constituyó como el movimiento social sobre el cual se habían volcado las actitudes críticas o no conformistas hacia el régimen dictatorial. En los últimos años, los trabajos sobre historia de los partidos políticos de izquierda, Osuna (2015) y Casola (2009; 2015) han dado cuenta de la continuidad y las particularidades de la actividad militante de partidos trotskistas y comunistas durante la última dictadura. Por otro lado, Luciani (2017) y Manzano (2017) han reconstruido heterogéneos espacios de participación política juvenil durante la última dictadura, mientras que Blanco y Vommaro $(2017 ; 2018)$ y Larrondo y Cozachcow $(2017)$ han focalizado han analizado las militancias juveniles durante la década de 1980.

${ }^{6}$ Los testimonios fueron construidos a partir de entrevistas en profundidad, en su mayoría realizadas por nosotros o bien disponibles en acervos orales de las facultades. La muestra general reúne 58 testimonios de varones (41) y mujeres (17) que cursaron carreras de grado en las facultades de la UBA entre 1974 y 1983, con (37 casos) y sin militancia (21 casos) política universitaria. Los y las entrevistadas autorizaron a utilizar su nombre y apellido, opción que sostenemos en función de la relevancia de sus trayectorias de militancia. Cuando no brindamos apellido, se trata de un pseudónimo a pedido de la o el entrevistado. En este artículo citamos 11 testimonios, todos
} 


\section{Guadalupe Seia}

retomamos y reflexionamos sobre la bibliografía especializada, tanto clásica como reciente.

\section{Gratuidad y expansión universitaria (1949-1976)}

En Argentina, la gratuidad universitaria había sido dispuesta en 19497, hasta entonces, los estudiantes debían abonar tarifas diferenciadas por derechos de inscripción anuales; por derechos de cursar trabajos prácticos y rendir exámenes; de utilización de la biblioteca; también, por trámites varios como la habilitación de títulos y la emisión de certificados. Estos fueron eliminados definitivamente en 1953. (Pis Diez, 2019). En el marco del proyecto universitario peronista que cuestionaba los principios reformistas en el funcionamiento de las casas de altos estudios, la erradicación de los aranceles fue recibida con cierta "indiferencia" por parte del movimiento estudiantil (Pis Diez, 2019), aún cuando la gratuidad de la educación superior se había constituido tempranamente como una consigna del reformismo (Buchbinder, 2018). En ese contexto, desde las federaciones se postulaba la necesidad de becas y mayor presupuesto universitario para solventar los gastos más onerosos que implicaban estudiar una carrera universitaria (pensionados, bibliotecas, comedores, etc.). ${ }^{8}$

Entre 1949 y 1955 la matrícula universitaria se triplicó (Cano, 1985). El sistema universitaria argentino se consolidó como uno de masas en el marco de un proceso regional y global de expansión universitaria. A pesar de las transformaciones que tuvieron lugar en las casas de altos estudios a partir del golpe de estado autodenominado como "Revolución Libertadora" (1955), la gratuidad no fue cuestionada a nivel de la legislación hasta 1967 cuando un nuevo régimen autoritario sancionó la Ley Orgánica de Universidades Nacionales № 17.245. La misma eliminó el voto de la representación estudiantil en el cogobierno, estableció exámenes de ingreso y definió a la gratuidad como un régimen al que se accedía tras aprobar un número de materias determinado, según lo fijara cada universidad (Pis Diez, 2019). La Federación Universitaria Argentina (FUA) denunciaba al gobierno dictatorial por, entre otras cosas, haber atentado contra la gratuidad con medidas como las restricciones presupuestarias, los subsidios a las universidades privadas, el cierre de los comedores estudiantiles, la disminución del número de becas, etc. (Seia, 2014).

Asimismo, la dictadura de la autodenominada "Revolución Argentina" aspiró a reducir la matrícula universitaria como parte de su programa para revertir la "infiltración comunista" de los claustros (Califa y Seia, 2018). Sin embargo, la lucha

construidos en entrevistas realizadas por nosotros en 2015 y 2017 en la ciudad de Buenos Aires. Para mayores precisiones sobre la muestra y el proceso de construcción de las fuentes orales, véase Seia (2019).

${ }^{7}$ Ley Universitaria № 14.297 (1954) reafirmó la gratuidad (Friedemann, 2019).

${ }^{8}$ Para análisis sobre el movimiento estudiantil durante los primeros dos gobiernos peronistas, véase Toer (1988), Califa (2014) y Pis Diez (2018). 


\section{"La educación es un derecho, no un privilegio": la lucha estudiantil contra el arancel universitario durante la última dictadura en Argentina (1980- 1983)}

estudiantil contra la política bautizada como "limitacionista", logró superar los cupos pre-fijados para el ingreso universitario, colaborando con un nuevo ciclo expansivo del sistema universitario. ${ }^{9}$ Esta victoria se cristalizó en la Universidad de Buenos Aires cuando en 1973 se dispuso el ingreso irrestricto para el ciclo lectivo siguiente. En paralelo, el artículo tres de la Ley № 20.654/1974 estableció la gratuidad sin requisitos. Dicha legislación también impulsó la "asistencia social a la comunidad universitaria" e instauró un "sistema de becas" que incluía ayudas económicas, becas estímulos, asignación a la familia del estudiante ${ }^{10}$, becas para estudiantes extranjeros y becas de honor (Friedemann, 2019). ${ }^{11}$

Sin embargo, los aspectos progresivos de dicha legislación apenas llegaron a ponerse en práctica debido a que ya desde mediados de 1974 la gestión ministerial de Oscar Ivanissevich definió nuevas intervenciones en las universidades nacionales. En la UBA se desplegó un operativo de "depuración" coordinado por Alberto Ottalagano, el rector designado para "sanear los claustros" de la "amenaza comunista" (Friedemann, 2015; Seia, 2016). En ese marco, fueron re-instituidas las limitaciones al ingreso universitario a través del establecimiento de cupos, aunque no se dio marcha atrás con la gratuidad. El movimiento estudiantil condenó el retroceso hacia la "universidad elitista", sin lograr revertir las medidas. La matrícula porteña inició una tendencia de caída, agudizada durante la última dictadura (Seia, 2018; Friedemann, 2019). ${ }^{12}$

\section{Una universidad anti-reformista y excluyente $(1976-1983)^{13}$}

Las Fuerzas Armadas (FFAA) intervinieron las universidades nacionales pocos días después del golpe de estado, designando delegados primero miembros de las fuerzas y luego civiles que eran parte del cuerpo docente de cada casa de estudios.

\footnotetext{
${ }^{9}$ Califa y Seia (2017) han matizado que la expansión de la matrícula universitaria entre 1971 y 1973 se deba a la creación de nuevas universidades (Friedemann, 2019). La participación de las nuevas unidades académicas en la matrícula total fue relativamente pequeña durante sus primeros años de existencia, a la vez que en muchos casos se trató de casas de estudios nacionalizadas que ya eran parte del sistema (Mendonça, 2017).

${ }^{10}$ Este tipo de asignación resulta interesante de considerar en tanto que no se constituyó como una reivindicación extendida en el movimiento estudiantil argentino. En contraste, el movimiento estudiantil español durante la década de 1970, años identificados como tardofranquismo, exigía al gobierno de transición que los estudiantes recibieran un salario para compensar el ingreso que perdían las familias cuando los jóvenes dejaban de trabajar para estudiar.

11 Esta legislación incluyó una serie de puntos fuertemente cuestionados por el movimiento estudiantil debido a su carácter represivo y de potencial amenaza a la autonomía universitaria. Sobre el contenido de la ley, su proceso de discusión y las críticas a la misma, véase Buchbinder (2014).

${ }^{12}$ Sobre el debate en torno a los cambios en el movimiento estudiantil porteño durante el tercer peronismo, véase Millán (2016; 2018) y Dip (2017).

13 Para un abordaje en detalle de cada una de las líneas de acción desarrolladas en la UBA por la dictadura, véase Seia (2018a; 2018b; 2017). Laura Rodríguez (2015) propone un abordaje general de la política universitaria de la dictadura, incorporando el estudio de diversas casas de estudio.
} 


\section{Guadalupe Seia}

Desde el Ministerio de Cultura y Educación se diagnosticó un "problema universitario" que tenía dos facetas principales: la "infiltración comunista" de los claustros y su crecimiento "desmedido y desordenando", que asimismo potenciaba el "accionar subversivo" en las casas de estudio (Seia, 2019a).

La respuesta al "problema universitario", entonces, combinó la represión feroz sobre la militancia estudiantil ${ }^{14}$, la "depuración" del cuerpo docente y no docente de las unidades académicas y la prolongación de la prohibición de la actividad política y gremial en las universidades ${ }^{15}$, por un lado. Por otro, se dispuso el funcionamiento de las casas de estudio subordinado a la voluntad de la Junta Militar de Gobierno y sus delegados civiles, eliminando cualquier atisbo de autonomía universitaria (Seia, 2018b), y se avanzó en un proceso de "re-dimensionamiento" de la matrícula estudiantil que consistió en su achicamiento a través de la imposición de cupos (Seia, 2018a). La UBA se vio particularmente afectada por esta política, donde cada año quedaban afuera alrededor de treinta mil aspirantes. La matrícula de esta institución cayó de 146.909 estudiantes en 1976 a 106.793 en 1983 (Véase Tabla 1).

Tabla 1. Matrícula, ingresantes, cupos y aspirantes de la UBA (1973-1984)

\begin{tabular}{ccccc}
\hline Año & Matrícula* & Ingresantes** & Cupos*** $^{* *}$ & Aspirantes*** \\
\hline 1973 & 133.272 & 36.239 & Irrestricto & ---- \\
\hline 1974 & 166.215 & 40.535 & Irrestricto & ---- \\
1975 & 152.863 & 30.028 & 29.000 & 33.456 \\
1976 & 146.909 & 20.789 & 10.500 & 27.869 \\
1977 & 134.224 & 11.647 & 13.845 & 24.983 \\
1978 & 117.360 & 11.956 & 12.380 & 40.075 \\
1979 & 114.550 & 11.163 & 11.050 & 46.312 \\
1980 & 108.387 & 10.866 & 9.830 & 38.473 \\
1981 & 110.286 & 11.422 & 9.830 & 39.473 \\
1982 & 102.766 & 14.526 & 10.145 & 41.065 \\
\hline 1983 & 106.793 & 15.815 & 9.780 & 44.884 \\
\hline
\end{tabular}

\footnotetext{
14 Según el Registro Unificado de Víctimas del Terrorismo de Estado (RUVTE), sólo para las facultades, 926 personas que trabajaban y/o estudiaban en la UBA fueron asesinadas y/o desaparecidas entre el 24 de marzo de 1976 y el 10 de diciembre de 1983. Esta cifra fue obtenida al omitir las reiteraciones de las personas que aparecen en las nóminas de diversas unidades académicas y/o en los listados de graduados y docentes de forma simultánea construidas por el RUVTE. Agradecemos la colaboración del Ingeniero Joaquín Seia en el análisis de los datos.

15 Las agrupaciones, centros y federaciones estudiantiles fueron ilegalizadas en 1976. De todos modos, se ha descripto que estas organizaciones sostuvieron cierto nivel de actividad por fuera de las facultades debido a la incesante vigilancia que allí se instaló. Las mismas desarrollaron diferente tipos de actividades (Seia, 2019a).
} 
"La educación es un derecho, no un privilegio": la lucha estudiantil contra
el arancel universitario durante la última dictadura en Argentina (1980-
1983)

$\begin{array}{llll}1984 & 150.938 & 40.096 & \text { Irrestricto }\end{array}$

Fuente: Elaboración propia.

* Datos brindados por el Dpto. de Información Universitaria, Sec. de Políticas Universitarias,

Ministerio de Educación (2018). El censo de la UBA informa que la matrícula de 1980 era de 95.255

estudiantes.

** Datos brindados por la UBA. Series estadísticas $N^{\circ} 5$

*** Datos brindados por el Diario La Nación (1975-1983)

Este modelo de universidad anti-reformista, despolitizada, pequeña, excluyente y más sencilla de vigilar se intentó cristalizar mediante la sanción en 1980 de la ley $\mathrm{N}^{\circ}$ 22.207 de Régimen Orgánico de Universidades Nacionales. ${ }^{16}$ Entre los aspectos más cuestionados, además de las características inconsultas del proceso de elaboración y aprobación de la norma, se encontraban la inexistencia de co-gobierno, la amenaza permanente de intervención del Poder Ejecutivo y la legalización de los cupos y el cobro de aranceles para ingresar y cursar carreras de grado en las universidades nacionales.

La política de arancelamiento fue otra de las modalidades que adquirió la política de "re-dimensionamiento" del sistema universitario (Cano, 1985; Buchbinder y Marquina, 2008; Soprano y Rodríguez, 2009; Rodríguez, 2015). Se trató de una medida regresiva en tanto el nivel de grado era gratuito desde mediados de siglo y había sido uno de los factores centrales en el crecimiento de la matrícula universitaria. Esta política fue interpretada como un paliativo a la dificultosa situación económica que atravesaban las universidades nacionales producto de una caída del aporte del Estado Nacional en su presupuesto. ${ }^{17}$

Sin embargo, ya desde hacía años, el estudiantado de la UBA debía abonar para acceder a una serie de servicios y trámites elementales para avanzar en sus carreras (fotocopias, certificados, legalizaciones, uso de computadoras y laboratorios, realización de trabajos prácticos en laboratorios, actividades deportivas, jardín maternal, etc.). Estos montos se actualizaban en paralelo al proceso inflacionario que atravesaba el país y a la caída del presupuesto universitario. A esto se sumó que desde 1980, los aspirantes al ingreso debieron abonar un arancel específico para tener derecho a los cursos y el examen de ingreso. ${ }^{18}$ En 1981, el rectorado de la UBA aprobó los aranceles para las todas carreras de grado de las facultades. ${ }^{19}$ Respecto del plan de becas para estudiantes, se reglamentó que las mismas serían adjudicadas por diez meses. La facultad le asignaría a cada becario un consejero de estudios que

\footnotetext{
16 Sobre ley y sus críticas a la misma, véase Rodríguez (2015) y Seia (2017).

${ }^{17}$ La revista católica Criterio afirmaba que el arancelamiento contaba con el apoyo del Ministerio de Economía, empeñado en reducir drásticamente el gasto público corriente y en limitar el nivel de inversión pública. Asimismo, describían que la medida era defendida por los rectores ante la escasez de recursos financieros con que contaban (n. 1799, noviembre de 1979).

${ }^{18}$ Resolución Rectoral UBA (RRU) N775, 26/11/1979; N797, 27/11/1980.

${ }^{19}$ RRU N$^{\circ} 95,20 / 03 / 1981 ; N^{\circ} 110,31 / 03 / 1981$.
} 


\section{Guadalupe Seia}

debía informar regularmente el rendimiento académico del alumno. ${ }^{20}$ Según la normativa, las sumas recaudadas en concepto de arancel se aplicarían a la financiación del sistema de becas y subsidios de la universidad, previa deducción de los gastos que representaban los costos de implementación y control. ${ }^{21}$ El establecimiento del arancel causó críticas bastantes extendidas y, como veremos, potenció la organización y movilización estudiantil. En ese sentido, consideramos importante ponderar a esta política más allá de sus efectos económicos ${ }^{22} \mathrm{o}$ institucionales, en tanto la misma tuvo una significación crucial en el proceso de reorganización del movimiento estudiantil, así como también en la construcción de su pliego de reivindicaciones.

\section{La militancia estudiantil de la UBA entre 1976 y $1980^{23}$}

Entre 1976 y 1978 se dieron el noventa por ciento de las desapariciones y detenciones de los y las trabajadores y estudiantes de las facultades de la UBA. En los claustros, mediante la presencia permanente de agentes de la Policía Federal y de las Fuerzas Armadas se procuró instalar un clima de miedo entre el estudiantado junto a la demonización de la política en la universidad, identificada como una de las causas del "caos y la violencia" que allí se había extendido. ${ }^{24}$ En sus testimonios, los y las militantes universitarios durante esos años recuerdan las dificultades para generar vínculos de confianza y solidaridad entre compañeros, así como también conversar de temas por fuera de la currícula. ${ }^{25}$ A pesar de los riesgos, quienes pertenecían a las organizaciones estudiantiles buscaron estrategias para ir rompiendo con la consigna de que a la universidad sólo se iba a estudiar. ${ }^{26}$

\footnotetext{
${ }^{20}$ RRU N480, 03/08/1981; Nº17, 06/10/1981.

${ }^{21}$ Rodríguez (2015) detalla que el rector de la Universidad Nacional de La Plata afirmaba que apenas le sobraban fondos luego de deducidos los costos implicados en la aplicación del arancel.

${ }^{22}$ Vale destacar que numerosos testimonios se refirieron al arancel como un monto exiguo con difusos recuerdos respecto de si lo pagaron efectivamente o no.

${ }^{23}$ En adelante cuando nos referimos a las agrupaciones y los centros de estudiantes nos estamos refiriendo a aquellas organizaciones político-gremiales con actividad en las facultades de la UBA. Del mismo modo cuando nombramos ciertas facultades y no se especifica que se trate de unidades académicas de otras universidades, hacemos referencia a las de la UBA. Aquí presentamos una caracterización sintética sobre los años señalados. Hemos optado por no incluir un análisis detallado de las iniciativas desarrolladas por las agrupaciones y los centros de estudiantes, entre ellas las actividades recreativas y culturales y el desarrollo de las revistas estudiantiles. Para un análisis en profundidad, véase Seia (2019a).

${ }^{24}$ Sobre la represión sobre la comunidad de la UBA y las reconfiguraciones de la vida universitaria bajo la intervención durante la última dictadura, véase Seia (2019b; 2019c). En el presente artículo focalizamos sobre la acción colectiva del estudiantado contra la política universitaria de la dictadura. La misma encontró ciertos límites y ciertos márgenes de organización y actividad en el marco del terrorismo de estado. De este modo, a continuación proponemos una reconstrucción empírica que cuestiona las visiones extendidas acerca de la vida en las facultades como pura oscuridad, silencio y terror.

${ }^{25}$ Entrevistas a J.P. Paz (FJC), I. Celotto (UJS), V. Cipolla (FM), P. Alabarces (MTU), I. Medina (JUP), entre otras.

${ }^{26}$ En 1978, el gobierno dictatorial emitía una serie de propagandas televisivas haciendo referencia a la realidad universitaria. En una se veía cómo un estudiante varón, vestido con saco y corbata tiraba
} 


\section{"La educación es un derecho, no un privilegio": la lucha estudiantil contra el arancel universitario durante la última dictadura en Argentina (1980- 1983)}

En ese marco, entre 1976 y 1980, el movimiento estudiantil de la UBA, golpeado por la represión, buscó mantener su actividad al menos parcialmente a través de sus estructuras organizativas históricas. Si bien prácticamente todas las agrupaciones estudiantiles fueron ilegalizadas, las diferentes tendencias políticas atravesaron situaciones heterogéneas. La Juventud Universitaria Peronista (JUP) había sufrido con fuerza el embate de la Alianza Anticomunista Argentina ya antes del golpe de estado, y en la mayoría de las facultades no había conseguido participar de los comicios de centro de estudiantes de 1975 (Millán, 2018). En los meses posteriores al 24 de marzo de 1976, en facultades como Arquitectura, las células peronistas vinculadas a Montoneros procuraron desarrollar algunas acciones de resistencia 0 "defensa activa" contra la dictadura y la intervención universitaria (Seia, 2019a). ${ }^{27}$ Sin embargo, para 1977 lo que quedaba de la JUP había sido desarticulado producto de la represión y del movimiento de militantes universitarios a otros frentes políticos (Saadi, 2004). ${ }^{28}$

En contraste con la situación de la tendencia revolucionaria del peronismo, la agrupación Franja Morada ${ }^{29}$ vinculada a la Unión Cívica Radical (UCR) había logrado la presidencia de tres centros de estudiantes en los comicios de 1975, consolidando su posición a nivel de la UBA ${ }^{30}$, mientras que la Junta de Gobierno no había dispuesto su ilegalización. Este sector venía insistiendo con un posicionamiento contra el terrorismo y la violencia de "ambos signos" que sostenían golpeaba a las facultades. Este discurso era compartido por el Movimiento de Orientación Reformista (MOR), la agrupación universitaria del Partido Comunista (PC) que también había obtenido la presidencia en tres centros en 1975. Si bien el MOR había sido ilegalizado, el PC como la UCR sólo habían sufrido la suspensión de sus actividades ${ }^{31}$, de este modo,

\footnotetext{
a la basura un volante de una agrupación estudiantil al tiempo que afirmaba "Yo vengo a estudiar". (Opción, "Yo vengo a estudiar", n. 7, septiembre de 1978, p. 6). En otra se sostenía: "Dos años de estudio, de paz, de una realidad que armoniza la fuerza de la vocación con la dedicación responsable. Dos años durante los cuales los estudiantes se dedicaron exclusivamente a capacitarse para un futuro, antes incierto y ahora promisorio. 24 de marzo de 1978, segundo aniversario del Proceso de Reorganización Nacional. Dos años en que la Argentina recupera su histórico camino de libertad.". (Disponible en: https://www.youtube.com/watch?v=E1TS6llTZ3A. última consulta: 24/03/2020). Para un análisis sobre el uso de la propaganda y los medios de comunicación por la última dictadura, véase Risler (2018).

27 Volantes y obleas de las Milicias Montoneras de la Facultad de Arquitectura y Urbanismo, 19761977; registros del decano interventor sobre la "actividad subversiva" dicha unidad académica, 1976-1977. Sobre la política de "defensa activa” montonera, véase Gillespie (1987).

28 Entrevista a Irma Medina, militante JUP, 2017.

29 Beltrán (2013) realiza un recorrido por la historia de esta organización, mientras que Polak y Gorbier (1994) analizan los cambios que atravesó la agrupación durante la última dictadura.

30 Sobre los comicioes estudiantiles de 1975, véase el análisis de Millán (2018).

${ }^{31}$ Casola (2015) describe que el PC sostuvo un intenso nivel de actividad durante toda la dictadura, tanto en el movimiento obrero y estudiantil, como en las organizaciones de mujeres y de Derechos Humanos. La misma, sostiene, no se orientó a fortalecer la oposición a la dictadura, sino a defender a la denominada "fracción moderada" dentro de la Junta Militar contra la imposición del "ala fascista". En ese sentido, desde el partido se buscó promover el "diálogo" entre los militares y los jóvenes comunistas a partir del semanario Vamos publicado durante 1976 (Manzano, 2017; Saraniti, 2018).
} 


\section{Guadalupe Seia}

las agrupaciones estudiantiles contaban con un marco institucional que amparaba y en cierta medida, protegía a sus militantes. ${ }^{32}$

Dichas agrupaciones estuvieron en mejores condiciones para continuar reuniéndose y también para mantener en actividad a los Centros de Estudiantes que presidían. Así, en Ciencias Económicas, Arquitectura, Medicina, Ciencias Exactas y Naturales, Farmacia y Bioquímica, comunistas y radicales desarrollaron actividades de carácter gremial (venta de apuntes, presentación de petitorios) y recreativo (organización de pic-nics, peñas, torneos deportivos, etc.) desde los Centros de Estudiantes. ${ }^{33}$ No obstante, estas actividades no siempre eran publicitadas abiertamente y en muchas ocasiones eran impedidas por las fuerzas represivas en tanto las organizaciones y actividades gremiales estaban prohibidas por la legislación vigente. ${ }^{34}$ Es por eso que las Comisiones Directivas se reunían por fuera de los claustros en bares, sedes de los consejos o colegios profesionales o de los partidos políticos no ilegalizados..$^{35}$ Según la FJC, en 1977 funcionaban regularmente, aún ilegalmente, 60 Centros de Estudiantes universitarios en Argentina. ${ }^{36}$

Asimismo, el MOR/FJC y la FM avanzaron en acuerdos para reorganizar en 1977 la Federación Universitaria de Buenos Aires (FUBA). ${ }^{37}$ De este espacio también participaron otras tendencias políticas como la Juventud Socialista del Partido Socialista de los Trabajadores (JS/PST), la Juventud Comunista Revolucionaria del Partido Comunista Revolucionario (JCR/PCR), la primero Tendencia Estudiantil Revolucionaria Socialista y luego la Unión de Juventudes por el Socialismo del Partido Obrero (TERS-UJS/PO) y el Movimiento Nacional Reformista del Partido Socialista. ${ }^{38}$ Vale destacar que a diferencia del comunismo, el radicalismo y el socialismo, los partidos y agrupaciones universitarias trotskistas y maoístas fueron ilegalizados. ${ }^{39}$ A pesar de ello, fundamentalmente estas agrupaciones procuraron continuar con su actividad organizativa y política en un marco de semi-

\footnotetext{
La Federación Juvenil Comunista (FJC) fue una de las agrupaciones fundamentales para el sostenimiento en actividad del movimiento estudiantil durante toda la dictadura (Gilbert, 2009).

32 Esto no implica que la represión no recayó sobre los miembros de sus organizaciones.

${ }^{33}$ Entrevistas a J.P. Paz, P. Geli (FJC), 2015; V. Cipolla, F. Storani, L. Luchilo, J. Demichelis (FM), 2017.

${ }^{34}$ Por ejemplo, el pic-nic del día de la primavera organizado por el CECEN en 1979 fue interrumpido por la Policía Federal y tuvo un saldo de la totalidad de los asistentes detenidos en la propia Ciudad Universitaria (Entrevista a J.P. Paz (FJC), 2015).

${ }^{35}$ A modo de ejemplo, el Colegio Profesional de Ciencias Económicas albergó durante toda la etapa a la Comisión Directiva del CECE (Beltrán, 2013; entrevista a M. Buckley (FM), 2017).

${ }^{36}$ Imagen, "En una universidad en crisis, ¿qué hacen los estudiantes?", 1977, s.p.

37 Respecto de la Federación Universitaria Argentina (FUA), estas mismas organizaciones a nivel nacional acordaron designar como presidente a Marcelo Marcó de la FM y conformar una Junta Representativa Unificada de la que formaban parte la FJC/MOR y el MNR/PS (Gómez, 1995; Beltrán, 2013). Recordemos que FUA se encontraba partida en dos desde 1971 (Califa, 2017). Sobre los debates respecto de la orientación política de la FUA durante la dictadura, véase Seia (2019a). A grandes rasgos, la izquierda trotskista denunciaba el "participacionismo" y "dialoguismo" promovido por el comunismo y el radicalismo que dirigían la FUA. A pesar del contexto dictatorial, dichas agrupaciones exigían "romper con la parálisis" para enfrentar la política represiva y "limitacionista" del régimen.

38 Opción, "Vuelve la FUBA", n. 4, junio de 1978.

${ }^{39}$ Sobre las reconfiguraciones del PST durante la dictadura, véase Osuna (2015).
} 


\section{"La educación es un derecho, no un privilegio": la lucha estudiantil contra el arancel universitario durante la última dictadura en Argentina (1980- 1983)}

clandestinidad. A nivel universitario, los grupos de izquierda trotskistas tuvieron mayor inserción temprana en unidades académicas como Filosofía y Letras y Psicología. ${ }^{40}$

También en 1977, dichas fuerzas políticas, aunque con distinta presencia en cada facultad, participaron de la conformación de las Comisiones Reorganizadoras de los Centros de Estudiantes allí donde no había habido elecciones en 1975 o bien no había sido posible sostener el funcionamiento del mismo luego del golpe de estado. ${ }^{41}$ Las mismas también se reunían por fuera de las facultades. Desde allí se fue entretejiendo una red colaborativa entre militantes de las agrupaciones en pos de objetivos comunes, inicialmente, la legalización del Centro de Estudiantes, el fin de la presencia policial y un número de reivindicaciones gremiales que también enarbolaban los Centros Estudiantes y las federaciones. Estas organizaciones demandaban la ampliación de la oferta horaria de cursada, incrementar el presupuesto para educación para aumentar el monto y el número de las becas y los sueldos del personal docente y no docente, mejorar el funcionamiento de los comedores, etc. ${ }^{42}$ La cuestión del ingreso fue especialmente denunciada debido a que cada año miles de aspirantes que quedaban afuera de la universidad. ${ }^{43}$ La federación proponía el ingreso de todos los que aprueben el examen y la eliminación de los cupos arbitrarios. ${ }^{44}$ También se denunciaba la situación de los estudiantes presos y desaparecidos, solicitando su libertad. ${ }^{45}$

En función de esta descripción es factible comenzar a cuestionar las afirmaciones acerca del fin del movimiento estudiantil a partir del golpe de estado de 1976. Observamos el esfuerzo de la militancia estudiantil por sostener aún con dificultades y en condiciones de clandestinidad la actividad de las organizaciones políticas y entidades gremiales. Esto es fundamental para comprender la

\footnotetext{
40 Entrevistas a D. Sierra, P. Mauas, I. Celotto, H. Díaz (UJS), 2015 y 2017; Sergio, Claudia (JS/PST), 2017.

41 En Derecho, la Comisión se constituyó durante el año 1977 con la participación de la FJC, la FM y los sectores universitarios del Partido Intransigente y el PST. En Ingeniería y Filosofía y Letras convivieron dos comisiones por facultad. En la primera estaba la CRECEI, orientada por FJC/MOR y la CERCEI, vinculada a FM. En la segunda facultad, existía la CRECEFYL, orientada por agrupaciones trotskistas, y la Pro-CEFYL, promovida y orientada por la FJC con la participación del peronismo y el radicalismo. (Clarín, 06/10/1982, s.p.; Gómez, 1995; Dalmazzo, 1995; Polak y Gorbier, 1994).

42 Imagen, "Cursos de apoyo y desaliento", n. 11, 17/02/1978, p. 4, "Los olvidos del ministro", n. 14, 21/04-04/05/1978, p. 4, "La opinión estudiantil”, n. 14, 21/04-04/05/1978, p. 4; Opción, "Catalán: el Martínez de Hoz de la enseñanza”, op. cit.

43 Imagen, "Igual que el PRODE”, n. 13, a. II, 6-20/04/1978, p. 5, “Universidad: cada vez menos”, "Los olvidos de un ministro", n. 14, 21/04-04/05/1978, pp. 4-5.

44 Imagen, "Vía libre a los que aprueben", n. 12, /03/1978, p. 4; Opción, "Vuelve la FUBA", n. 4, junio de 1978, s.p., "Petitorio en Psicología", n. 5, julio de 1978, s.p., "Por la defensa del movimiento estudiantil", n. 8, octubre de 1978, s.p.

45 Volante del CEA, "Denunciemos los secuestros y torturas a la Comisión de la OEA el 7/9-9 hs. Todos a Av. De Mayo 760", 06/09/1979; Volante, “A los universitarios argentinos", Comisión Interuniversitaria de DDHH, 1979; Imagen, "Denunció la FUA", n. 50, 6-18/10/1979, p. 2, "Dos 'casos' que preocupan”, n. 20, 01-17/07/1978, pp. 4-5, "El silencio no es respuesta”, n. 48, 07-21/09/1979; Opción, “Lo que perdimos, lo que debemos reganar”, n. 16, noviembre de 1979, pp. 14-15.
} 


\title{
Guadalupe Seia
}

relativamente rápida y activa respuesta estudiantil contra el arancelamiento de los estudios de grado. A la vez, nos permite problematizar las ideas de refundación del movimiento estudiantil bajo la dictadura en tanto hemos dado cuenta de continuidades respecto de las modalidades de organización así como también de buena parte de las fuerzas políticas con preponderancia en el ámbito universitario.

\section{Contra el arancel: organización y movilización en la UBA (1981-1983)}

Cuando en 1980 se conoció la sanción de la ley, la amenaza del arancelamiento se sintió de inmediato entre el estudiantado porteño, y las diversas agrupaciones políticas que desarrollaban actividades hasta ese momento condenaron esa posibilidad e iniciaron su militancia contra la medida.

\begin{abstract}
“El arancelamiento no mejorará la situación presupuestaria. Su aplicación constituye una violación al derecho constitucional al estudio. Es un paso más al criterio de "subsidiariedad del estado" sostenido desde el palacio de hacienda y como uno de sus más graves efectos, hipotecará la formación de científicos y técnicos requeridos para cualquier proyecto de desarrollo nacional independiente." 46

"El argumento oficial de que el arancel contribuirá a otorgar igualdad de posibilidades para estudiar quedó descalificado al conocerse el nuevo recorte del porcentaje del presupuesto nacional destinado a educación. La implantación del arancelamiento corresponde al espíritu de la ley universitaria sancionada hace un año, que legaliza el limitacionismo y la falta de democracia en la universidad." 47
\end{abstract}

Para las agrupaciones trotskistas (UJS/PO y JS/PST), el proyecto oficial expresaba el carácter "antipopular y antidemocrático" del régimen ya que cada vez se quedaba mayor cantidad de jóvenes por fuera de la educación superior. Estaba en riesgo el acceso a la enseñanza como un derecho garantizado por la constitución nacional. ${ }^{48}$ En este punto coincidía la FJC que planteaba que, si a los crecientes costos corrientes de estudiar se sumaba el del arancel, el resultado inevitable sería el aumento de la deserción, particularmente la de los sectores de menores recursos. ${ }^{49}$ Asimismo, estas agrupaciones de la izquierda universitaria, daban cuenta de la imbricación entre la ley universitaria y el arancel, que surgió como posibilidad concreta a partir

\footnotetext{
${ }^{46}$ Volante del Centro de Estudiantes de Arquitectura (CEA), "La educación... ¿es un privilegio?”, circa $1979 / 1980$.

${ }^{47}$ Volante CEA, 31/03/1981.

${ }^{48}$ Opción, "Se vienen los aranceles", n. 20, junio de 1980, p. 9; “Aranceles, ¿educación para todos?”, n. 22, agosto de 1980, p. 9; "Plan de lucha FUA, un primer paso", n. 23, agosto de 1980, p. 9; "Universidad 1980: ruido en las aulas", n. 25, diciembre de 1980, p. 12; Nueva Generación, "Fuera la ley universitaria", n. 6, junio de 1980; “4 preguntas y respuestas sobre los aranceles", n. 7, 12/10/1980; "La FUA y la lucha contra los aranceles", n. 8, 06/12/1980.;

${ }^{49}$ Imagen, "Ahora a la facultad se va a pagar", n. 71, 28/08-10/09/1980; “QQué se oculta detrás del arancel?", n. 72, 11/09/-24/09/1980; "Aspiren nomás, que total el aire es gratis", n. 77, 20/1103/12/1981; “75 a 82”, n. 78, 04-16/12/1980.
} 


\title{
"La educación es un derecho, no un privilegio": la lucha estudiantil contra el arancel universitario durante la última dictadura en Argentina (1980- 1983)
}

de su sanción. Los matices surgían en el énfasis que el trotskismo realizaba sobre la vinculación entre las autoridades educativas, económicas y los militares a cargo del poder ejecutivo. Para este sector, resistir el arancelamiento y revocar la ley universitaria era parte de una batalla más amplia contra la dictadura.

En julio de 1980, la FUA se aprobó un plan de lucha nacional que incluida la organización de mesas redondas y asambleas, comisiones contra el arancel en el marco de los centros de estudiantes, la solicitud de entrevistas con sectores políticos y sindicales, y la realización de un acto público (sin fecha definida). ${ }^{50}$ El punto central del plan era la recolección de firmas de respaldo a un petitorio contra el arancel en todas las universidades nacionales. Las diversas tendencias políticas militaron activamente para reunir las firmas. En la UBA se estimaba haber reunido $4.000^{51}$, mientras que a nivel nacional, se contabilizaba entre 10.000 y 20.000 .52

Ya en 1981 cuando se oficializó el cobro del arancel en la UBA, la reacción estudiantil no se hizo esperar y potenció los niveles de organización logrados hasta ese momento. En las facultades las agrupaciones convocaron al "no pago del arancel" a través de una vía burocrática establecida en la normativa, la exención. Los estudiantes podían solicitar a las autoridades ser condonados del pago del arancel si argumentaban imposibilidades económicas. Esta opción funcionó como una "grieta" que las organizaciones estudiantiles aprovecharon como mecanismo "dentro de la norma" para rechazar el arancelamiento. Como argumento central, recurrían al derecho a aprender garantizado por la constitución nacional. Así, en sus publicaciones, llamaban a no pagar y compartían un modelo de nota para concretarlo:

\begin{abstract}
"Señor decano: Me dirijo a usted en virtud de lo dispuesto por la ley universitaria y la Reglamentación del Arancelamiento a fin de solicitar mi exención. Fundamento mi pedido en el hecho, señalado en la legislación citada precedentemente, de no contar con los recursos necesarios para abonar el arancel fijado, como paso a detallar más abajo A las razones expuestas quiero agregar los preceptos de la Constitución Nacional. En efecto, ésta en su artículo 14 establece el derecho de 'aprender'; y en el artículo 16 expresa que 'todos los habitantes son iguales ante la ley'. La imposición del arancel universitario, en la forma que ha sido establecido, viola ese derecho de aprender y el principio de igualdad, fijados por las cláusulas citadas." 53
\end{abstract}

\footnotetext{
50 Imagen, "Otra cosa es con plan de acción", n. 69, 31/07-12/08/1980, p. 15; "Mes de lucha”, n. 72, 11/09/-24/09/1980; "La FUA en acción”, n. 74, octubre de 1980; “El plan de lucha va”, n. 77, 20/11$03 / 12 / 1981$.

51 Minuta universitaria JS/PST, "Balance de estudiantil”, diciembre de 1980.

52 Las diversas fuentes brindan cifras contradictorias. Imagen, "La FUA en acción”, n. 74, octubre de 1980; "El plan de lucha va", n. 77, 20/11-03/12/1981; "Alguien se está haciendo el oso", n. 79, 18/12/1980-07/01/1981; Informe PCR, diciembre de 1981; Informe Estudiantil JS/PST, noviembre de 1981.

53 Hoja Estudiantil(JS/PST), "Presentar las exenciones, un primer paso para no pagar el arancel”, n. 1, abril de 1981. En el mismo sentido, también se promovió el pedido de las becas estipuladas por la reglamentación del sistema de aranceles (Volante Estudiantes Socialistas, “¡Que no se aplique el arancel!", 1981).
} 


\section{Guadalupe Seia}

En ese marco, las Comisiones Reorganizadoras, los Centros, las Comisiones de Ingresantes de las facultades organizaron reuniones donde la participación fue considerable. Desde allí, también se impulsó "no pago" y se conformaron Comisiones Contra el Arancel. ${ }^{4}$ Los militantes buscaron coordinar que aquellos estudiantes que acordaban con la medida presentaran la documentación en la facultad el mismo día y durante la misma franja horaria. ${ }^{55}$ De este modo, se generaba una concentración estudiantil para completar un trámite administrativo.

"Participaron más de 800/900 personas, muchas ... Lo que hicimos, porque había una pequeña brecha pero no podías hacer movilizaciones, entonces lo que hicimos es, como se podía pedir beca, juntarnos todos a la misma hora y pedir beca ... había toda una cola laaarga de gente." 56

\section{"Buenos Aires también pelea"}

Este proceso creciente de organización colectiva contra el arancel alcanzó un mayor desarrollo durante la segunda mitad de 1981. El 17 de septiembre se desarrolló una concentración de aproximadamente ciento cincuenta estudiantes en el centro porteño organizada por las Comisiones Reorganizadoras de Ingeniería, Filosofía y Letras, los Centros de Medicina, Ciencias Exactas y Farmacia, con la adhesión de la FUA y la FUBA. Los cánticos entonados se pronunciaron contra el rector porteño Lucas Lennon, los cupos de ingreso y el arancel. ${ }^{57}$

En octubre, la FUBA convocó a una movilización al Palacio Pizzurno donde se ubicaba el Ministerio de Cultura y Educación con el objetivo de entregar a las autoridades el petitorio junto a las firmas recolectadas a lo largo del último año. Se trató de la primera movilización callejera estudiantil en Buenos Aires bajo la dictadura. Uno de los volantes de la convocatoria se titulaba "Buenos Aires también pelea", destacando que las casas de estudio ubicadas en la entonces Capital Federal se sumaban a la movilización que venía desarrollándose en otras ciudades del país como Rosario y Córdoba. ${ }^{58}$

El veintidós de octubre, entonces, tuvo lugar el primer acto estudiantil público en la Facultad de Ciencias Económicas. Se repartieron volantes, se desplegó un cartel desde pisos superiores y los militantes de las diversas agrupaciones tomaron turnos

\footnotetext{
${ }^{54}$ Volante Estudiantes Socialistas, “iQue no se aplique el arancel!”, 1981. En octubre de 1980, la FJC contabilizaba 70 comisiones contra el arancel a nivel nacional, 36 en las facultades de la ciudad de Buenos Aires (Imagen, "La FUA en acción", op. cit.)

${ }^{55}$ Hoja Estudiantil, "Un comienzo de clases agitado", n. 1, abril de 1981; Entrevistas a Claudia, (JS/PST), 2017.

${ }_{56}$ Entrevista a Sergio (JS/PST), 2017.

${ }^{57}$ Aquí y Ahora, "Estudiantes en las calles", n. 16, 24/09-07/10/1981.

${ }^{58}$ Nueva Generación, "Por una gran movilización nacional", n. 11, 8 de noviembre de 1981, p. 2; Aquí y Ahora, "Habla el estudiante de la foto", n. 19, octubre/noviembre de 1981.
} 


\title{
"La educación es un derecho, no un privilegio": la lucha estudiantil contra el arancel universitario durante la última dictadura en Argentina (1980- 1983)
}

para hablar. ${ }^{59}$ Luego inició la movilización que partió desde Plaza Houssay con una concentración de entre doscientos y trescientos estudiantes, a los que se fueron sumando otros a lo largo del recorrido. El cartel que encabezaba la columna decía: "Queremos democracia en la universidad. No al arancel. Por la participación.". Entre los cánticos se escuchaban "libertad, libertad, queremos democracia en la universidad", "los centros de estudiantes, unidos y adelante", "se va a acabar, se va a acabar el arancel en la universidad", "Atención, atención, el único camino es la movilización", "FUA-FUBA, la lucha continúa".60

Una vez en las puertas del ministerio, mientras una delegación estudiantil presentaba el petitorio y un documento elaborado por la FUBA, fue la policía -que había seguido de cerca toda la movilización- la que puso fin a la concentración deteniendo a los presentes y golpeando a los reporteros gráficos, a la vez que destruían sus cámaras. En Ciudad Universitaria, ese mismo día, también se registró la detención de militantes estudiantiles. ${ }^{61}$ Ante dicho desenlace, el veintinueve de octubre, en la facultad de Ciencias Exactas y Naturales, el Centro de Estudiantes realizó una conferencia de prensa denunciando la represión a la movilización y, particularmente, la detención de sus militantes. ${ }^{62}$ Numerosas organizaciones políticas y asociaciones de periodistas se sumaron al repudio de lo ocurrido. ${ }^{63}$ Lo acontecido durante esas jornadas logró gran visibilidad y repercusión también entre el estudiantado:

\begin{abstract}
“Cuando volví a la facultad el bar era un hervidero. La gente preguntaba y participaba en las habladas por los cursos. Es que la movilización demostró que se puede. Que estuvimos juntos radicales, comunistas, peronistas y de otras corrientes. Que la gente nos rodeó de solidaridad, durante y después de la marcha." 64
\end{abstract}

Esta movilización fue relevante para la consolidación del proceso de rearticulación del movimiento estudiantil porteño así como también para su irrupción en la escena pública. Luego de la misma se desarrollaron nuevas iniciativas que potenciaron los niveles de organización. En Filosofía y Letras, por ejemplo, la Comisión Reorganizadora convocó a una concentración que reunió ciento cincuenta personas

\footnotetext{
${ }^{59}$ Nueva Generación, "La movilización del 22 en Capital”, op. cit.; Aquí y Ahora, "Habla el estudiante de la foto", op. cit.

60 La Nación, "Grave incidente en un acto estudiantil", 23/10/1981; Nueva Generación, "La movilización del 22 en Capital”, n. 11, 8 de noviembre de 1981, p. 3; Opción, "Al vasco Burundarena, la vaca le salió toro", n. 33, noviembre de 1981.

${ }^{61}$ Nueva Generación, "La movilización del 22 en Capital", n. 11, 8 de noviembre de 1981, p. 3; La Nación, "La Policía informó sobre la agresión a un fotógrafo",24/10/1981.

62 Aquí y Ahora, "Habla el estudiante de la foto", n. 19, octubre/noviembre de 1981; Opción, "Al vasco Burundarena...", op. cit.

63 Nueva Generación, "Declaración de la UJS: Repudiemos la represión policial.", "Por una gran movilización nacional", "Los periodistas se movilizan”, n. 11, 8 de noviembre de 1981; Declaración Juventud Socialista, "Posición de la Juventud Socialista en el plenario de la FUA", 11/11/1981.

64 Aquí y Ahora, "Habla el estudiante de la foto", op. cit.
} 


\section{Guadalupe Seia}

ante el decanato para presentar un petitorio con ochocientas firmas, obteniendo una respuesta positiva: las chequeras de aranceles al día no serían exigidas para realizar trámites administrativos en la facultad. 65

El reclamo contra el arancelamiento fue un elemento significativo en el proceso de reagrupamiento del movimiento estudiantil entre fines de 1980 y 1981 . Esta forma de acción disidente fue una de las primeras acciones de protesta desarrollada por el movimiento estudiantil que adquirió notoriedad pública en Buenos Aires. Con la movilización, las organizaciones estudiantiles expresaron públicamente que rechazaban varios aspectos de la política universitaria de la dictadura, cristalizada además en la ley universitaria.

Esta creciente movilización estudiantil contra la política universitaria de la dictadura debe insertarse en lo que Marina Franco (2018) denominó como el "inicio del giro opositor" durante 1981. La historiadora describe que las condiciones de mayor distención política que propició el presidente de facto Roberto Viola implicaron la aparición de cierta opinión pública y una notable activación social. Ese año es recordado como el "renacer" político y cultural posibilitado por la ampliación de libertades y la relajación de la censura. Dicha reactivación política tomó forma con el surgimiento de la Multipartidaria ${ }^{66}$ y de una creciente movilización sindical opositora, potenciado por el surgimiento de iniciativas y formas de encuentro social y cultural de "ánimo desafiante" o incluso anti-dictatorial.

Los planteos de la historiadora resultan iluminadores para pensar el fenómeno universitario y estudiantil específicamente. A lo largo de 1981 las autoridades universitarias buscaron desplegar nuevas estrategias hacia el "nuevo estudiantado" que ahora recordaban se componía de personas, promoviendo su participación en diversos aspectos de la vida en los claustros (Seia, 2019a). En la UBA, la Secretaría de Asuntos Estudiantiles fue cobrando importancia a partir del papel activo en el surgimiento de espacios de organización estudiantiles paralelos a las comisiones, agrupaciones y centros de estudiantes existentes. ${ }^{67}$ Asimismo, el clima de "apertura" promovido por el discurso del nuevo ministro de educación, Carlos Burundarena, generaba expectativas entre ciertos sectores del movimiento estudiantil, así como también un marco de una relativa y creciente "libertad" para actuar en los claustros. En ese contexto, se consolidaron formas organizativas estudiantiles previas,

\footnotetext{
65 Informe N¹ de la CRECEFyL, 26/10/1981; Nueva Generación, "Filosofía y Letras: Triunfó la movilización contra la 320", n. 11, 8 de noviembre de 1981.

66 En ese contexto, Larrondo y Cozachcow (2017) ubican el surgimiento del Movimiento de las Juventudes Políticas de los partidos políticos nacionales que funcionó bajo ese nombre entre 1983 y 1987.

${ }^{67}$ Se destacó la creación de revistas estudiantiles solventadas y coordinadas por las autoridades de cada facultad, así como también el impulso para la formación de agrupaciones estudiantiles ideológicamente afines al modelo universitario dictatorial, estás fueron denominadas como "agrupaciones independientes de derecha" o despectivamente como las "crías del proceso". Entre las revistas se destacó la experiencia de Base Cero de la Facultad de Ciencias Económicas y entre las agrupaciones no es posible soslayar a grupos como Iustum (Derecho), Quantum (Ingeniería), Sinapsis (Medicina), Nexo-Revalúo (Ciencias Económicas), Nobis (Filosofía y Letras), Línea de Agronomía Independiente (LAI), Lista Veterinaria Independiente, Estudiantes Independientes de la Facultad de Odontología, entre otras. Para un análisis de las mimas, véase Seia (2019a).
} 


\title{
"La educación es un derecho, no un privilegio": la lucha estudiantil contra el arancel universitario durante la última dictadura en Argentina (1980- 1983)
}

surgieron otras nuevas y se desplegaron acciones gremiales de carácter opositor hacia la política universitaria. En efecto, los propios militantes de diversas tendencias políticas coincidían en que 1981 los encontraba en una nueva situación:

\begin{abstract}
"Lo que sí es nuevo es que por primera vez desde 1976 centenares de compañeros se han reagrupado en diferentes facultades y universidades constituyendo comisiones pro-centro, coordinadoras, comisiones reorganizadoras ... expresando su voluntad de articular una respuesta a los ataques del gobierno y en particular ante la próxima aplicación de los aranceles."68
\end{abstract}

\section{"La educación es un derecho, no un privilegio"}

La etapa final de la última dictadura en Argentina coincidió con un nuevo momento para el movimiento estudiantil de la UBA (Seia, 2016; Cristal, 2017). Las agrupaciones desembarcaron definitivamente en las facultades con actividades y convocatorias públicas, con mesas y carteles, con 'habladas' en comedores, bares y aulas. La guerra de Malvinas abrió una brecha, posibilitando a quienes ya venían formando parte de las agrupaciones y las comisiones pro-centro, generar nuevos espacios de intercambio con el estudiantado y consolidar los ya existentes. También, impulsó y consolidó la participación de un nuevo sector del estudiantado que carecía de experiencia política previa, algunos se sumaron a agrupaciones pre-existentes, otros confluyeron en la conformación de nuevas organizaciones, las llamadas "agrupaciones independientes". Por último, esta oportunidad política brindó margen de acción a sectores políticos como el Partido Intransigente o los grupos peronistas para insertarse en la vida política universitaria (Seia, 2019a).

Durante 1982 y 1983 la reivindicación estudiantil por el acceso a las carreras fue central en la UBA. Como mencionamos, las agrupaciones estudiantiles cuestionaron tempranamente y con insistencia la política "limitacionista" de la dictadura a partir del establecimiento de cupos sin otro criterio que el de reducir la matrícula estudiantil (Seia, 2019a). ${ }^{69}$ Las Comisiones de Ingresantes junto a las Comisiones Reorganizadoras, los Centros y las agrupaciones de izquierda exigieron, y lograron en algunos casos, que quienes hubieran aprobado los exámenes pudieran cursar a pesar de que el cupo se hubiera completado. Entre 1979 y 1983, los cupos pre-

\footnotetext{
${ }^{68}$ Nueva Generación, "La FUA y la contra los aranceles", n.8, 6 de diciembre de 1980, p.7. También: Imagen, "Cambio de clima", n. 75, 23/10-05/11/1980; Opción, "1980: se acabó la pasividad", n. 25, III, diciembre de 1980.

${ }^{69}$ Es interesante detenerse en que al hacerlo, las fuerzas políticas no recuperaban explícitamente la experiencia de lucha contra una política similar desarrollada durante la dictadura de la autodenominada "Revolución Argentina". Identificamos una operación de memoria por parte de la militancia que, consideramos, apostaba a despegarse de las ideas demonizadoras del movimiento estudiantil radicalizado de la década previa, así como también de los discursos sobre la peligrosidad del «sobre-dimensionamiento» de las universidades (Cristal y Seia, 2018).
} 


\section{Guadalupe Seia}

establecidos fueron superados por el número efectivo de ingresantes (Véase Tabla 1). Esta diferencia fue creciendo hacia el final de la dictadura producto de la movilización estudiantil de cada facultad, en 1983 lograron ingresar 6.035 aspirantes más por sobre el cupo de 9.780 fijado por las autoridades de la UBA.

Las críticas a los cupos, las irregularidades en el ingreso, las trabas a la permanencia, sintetizadas en la denuncia contra el "limitacionismo", se articularon directamente con las medidas de arancelamiento, en tanto esta era interpretada como una faceta abiertamente económica que limitaba el acceso y la permanencia de los estudiantes de menores recursos en las facultades. El cuatro de septiembre de 1982 se reunieron las regionales que confluían en la Junta Representativa de la FUA. Desde allí, se convocó a los estudiantes a bregar por el ingreso irrestricto, sin exámenes ni cupos, también por la fin del arancel sobre la enseñanza universitaria y la derogación de la ley 22.207 para la democratización de los claustros. Se definió también la realización de un nuevo plan de lucha a nivel nacional. ${ }^{70}$ El mismo se concentraba en la recolección de firmas en un nuevo petitorio que fue presentado ante el Ministerio de Cultura y Educación en la movilización del veintidós de octubre de ese año bajo la consigna "la educación es un derecho, no un privilegio". En ella se calculó que participaron 2.000 personas junto a los Centros de Estudiantes y las Comisiones Reorganizadoras de la UBA. ${ }^{71}$

En 1983 también se convocó desde la FUA a un plan de lucha nacional que tuvo una importante repercusión en Rosario, Córdoba, La Plata y Buenos Aires. Por fuera de la Capital Federal el nivel de movilización fue importante y tuvo continuidad por varios meses, articulándose con otras demandas estudiantiles hacia los rectorados de cada institución. ${ }^{72}$ En Buenos Aires, el Comité Reorganizador de la FUBA, los Centros de Estudiantes, las agrupaciones, los Cuerpos de Delegados, las Comisiones y la Junta Coordinadora de Ingresantes se movilizaron en dos ocasiones (diez y veintidós de marzo) al Ministerio de Cultura y Educación para presentar petitorios a las autoridades exigiendo "ingreso de todos los aspirantes, derogación del sistema cupos y mayor presupuesto". ${ }^{73}$

\footnotetext{
70 La Voz, "Enérgico reclamo del movimiento estudiantil”, 07/09/1982.

${ }^{71} \mathrm{La} \mathrm{Voz}$, "Ratifica la FUA el acto estudiantil del día 22", 09/10/1982; "Comienza una agitada semana por la movilización estudiantil", 18/10/1982; "Primera Concentración de la FUA desde 1976", 18/09/1982; "Petitorio Universitario", 20/09/1982; "Manifestación estudiantil por la derogación de la Ley Universitaria", 23/10/1982; La Nación, "Entusiasta marcha de estudiantes universitarios", 23/10/1982.

72 Clarín, "Movilización de la FUA. Ingreso a las universidades”, 15/02/1983.

73 Clarín, "La FUBA convoca a los aspirantes", 06/03/1983, "Masiva solicitud de los aspirantes al ingreso", 11/03/1983, "Marcha de protesta estudiantil”, 23/03/1983, "Concentración de universitarios", 20/03/1983; La Voz, "El ingreso irrestricto es el reclamo del estudiantado", 06/03/1982; La Nación, “Aspirantes al ingreso en la UBA realizaron una marcha”, 11/03/1983, "El ingreso en la UBA", 23/03/1983; Tiempo Argentino, "Realizan los estudiantes una marcha contra los cupos"; 10/03/1983, "Se cumplió la marcha de protesta estudiantil”, 11/03/1983, "Licciardo no recibió a la FUBA; movilización de estudiantes", 23/03/1983; Prensa Obrera, "Todos a la movilización del 10 de marzo en Pza. Houssay, a las 18 hs.”, n. 7, I, 04/03/1983, p.8; "Es posible ganar; ¡Abajo los cupos!”, n. 8, marzo de 1983, p. 11; “Nueva manifestación, el martes 22”, n. 9, 18/03/1983, p. 11, "Balance de la movilización nacional contra los cupos", n. 10, 25/03/1983, p. 9; Volante de la Juventud Peronista Universitaria (JPU), convocatoria a la marcha del 22/03/1983.
} 


\section{"La educación es un derecho, no un privilegio": la lucha estudiantil contra el arancel universitario durante la última dictadura en Argentina (1980- 1983)}

Para este momento las reivindicaciones estudiantiles eran articuladas en una crítica general a la política universitaria de la dictadura. La situación universitaria era entendida como un producto de las orientaciones impuestas en los últimos años. La condena a los regímenes excluyentes de ingreso y permanencia era articulada con una crítica a una universidad "elitista”, "anti-popular" y "pequeña”, "de espaldas al pueblo argentino". En cambio, se reafirmaba el derecho a la educación pública y gratuita, exigiendo mayoritariamente el ingreso para todos los aspirantes y el no arancelamiento de la educación superior. Con matices, las agrupaciones iban delineando cómo debía ser la universidad "democrática": sin aranceles, ni cupos, ni limitaciones para el ingreso, la cursada y el egreso de los jóvenes. ${ }^{74}$

Si la primera mitad de 1983, a nivel universitario, las movilizaciones se focalizaron contra el ingreso restringido, los meses siguientes a la par de las campañas electorales de las facultades para la renovación de las autoridades de los Centros de Estudiantes ${ }^{75}$, la cuestión del arancel tomó protagonismo entre las reivindicaciones estudiantiles. La mayoría de las agrupaciones estudiantiles se oponían al arancel y lo expresaban en sus plataformas electorales. Las mismas solicitaban el aumento del presupuesto educativo y universitario, así como la anulación de los aranceles. ${ }^{76}$ Incluso, la agrupación liberal Unión para la Apertura Universitaria (UPAU) sostenía que el estado debía garantizar los recursos para desarrollar las tareas educativas, exigiendo su derogación. ${ }^{77}$ Todos estos sectores exigían asimismo un sistema de becas con una mayor extensión y financiamiento estatal que el vigente. ${ }^{78}$ La movilización contra el arancel logró visibilidad, expresando una preocupación del estudiantado. ${ }^{79}$ En Filosofía y Letras, por ejemplo, la asamblea estudiantil

\footnotetext{
${ }^{74}$ Esta visión, compartida a grandes rasgos por la mayoría de las agrupaciones estudiantiles, no era sostenida por las nuevas "agrupaciones independientes de derecha". Estas reivindicaban un modelo universitario más próximo al propuesto por la dictadura. Al respecto, véase Seia (2019a) y Manzano (2018).

75 Para un análisis de los resultados de las elecciones de Centro de Estudiantes de la UBA durante 1983, véase Cristal (2017) y Seia (2019a).

76 Plataforma MAPU (Filosofía y Letras), "Programa", 1983; Programa FM-Corriente Nacional y Popular (Filosofía y Letras), 1983; Propuesta Lista Unitaria (UJS, GEI, MAS - Filosofía y Letras), 1983; Plataforma Electoral Movimiento de Transformación Universitaria (MTU) (Filosofía y Letras), 1983; Plataforma Lista de Unidad Antidictatorial (Frente de Agrupaciones Universitarias de Izquierda FAUDI-, Filosofía y Letras), 1983; La Nación, "La propuesta de GESTAR para Ciencias Veterinarias", 17/07/1983; "Un singular gobierno tripartito propone EDNA" (Derecho), 18/07/1983; Plataformas FM-Junta Coordinadora Nacional, 1983; Plataforma Agrupación Unidad (Sociología), 1983; Plataforma Frente Estudiantil Nacional y Popular (Derecho), 1983; Volante JPU, 1983; Plataforma Estudiantes para la Liberación Nacional (Filosofía), 1983.

77 Plataforma UPAU (Derecho), 1983.

${ }^{78}$ Las agrupaciones "independientes de derecha" coincidían en la necesidad urgente de un aumento considerable del presupuesto pero acordaban con las autoridades universitarias en que rigiera el principio de "solidaridad estudiantil" que suponía el pago de un arancel (Plataforma Iustum, Derecho, 1983; Entrevista a A. González Escudero (Nexo-Revalúo), 2017).

${ }^{79}$ Es interesante destacar que en las universidades privadas de la ciudad de Buenos Aires sus estudiantes se movilizaron por el congelamiento de los aranceles realizando concentraciones callejeras múltiples.
} 


\section{Guadalupe Seia}

decidió no pagar más el arancel.80 Para concretar la medida de protesta, los estudiantes entregaron las chequeras necesarias para abonar a las autoridades ya electas del Centro de Estudiantes. ${ }^{81}$ En Filosofía y Letras se reunieron mil seiscientas y seiscientas en Sociología, a pesar de que quienes militaban recuerdan que muchos de sus compañeros no estaban dispuestos a entregar las chequeras en caso de que se las solicitaran para realizar algún trámite o rendir examen..$^{82}$

Una situación similar se vivió en la organización de la "quema de chequeras". La misma fue impulsada por el Centro de Estudiantes de Filosofía y Letras y se sumaron los de Medicina y Ciencias Económicas. Con la participación de mil personas, la acción se realizó en las inmediaciones de la Plaza Houssay. ${ }^{83}$ Ante la realidad de incinerar la documentación que la universidad exigía para abonar los aranceles, en general hubo resistencia por parte el estudiantado para entregar las chequeras. Incluso, un militante de una agrupación "independiente de derecha" recuerda que los miembros de las agrupaciones que proponían la quema habían entregado una fotocopia. ${ }^{84}$ Para superar este obstáculo se idearon "chequeras gigantes" de cartulina que además lograban un mayor impacto visual que las originales. Se trató de uno de los actos estudiantiles más importantes de los últimos meses de la dictadura. 85

Las anécdotas respecto a la dificultad para obtener las chequeras nos permiten reflexionar sobre de los relativos "éxitos" de las autoridades universitarias, así como también las "zonas grises" de las actitudes del estudiantado hacia la política universitaria de la dictadura. ${ }^{86} \mathrm{~A}$ pesar de que una parte mayoritaria del estudiantado no estaba de acuerdo con el arancelamiento de la universidad, numerosos jóvenes (incluso algunos que militaban) se negaban a brindar su propia chequera para protestar contra dicha medida. En los testimonios de los y las militantes que recolectaban las chequeras se describen que entre sus compañeros había sentimientos de temor por represalias de las autoridades como no poder rendir exámenes o la pérdida de la regularidad, o bien ante la posibilidad de obstáculos administrativos por no tener la documentación de pago. Así si bien existían un descontento extendido para con el arancel, concretar acciones de protesta y de carácter "definitivo" como era la quema de las chequeras no era

\footnotetext{
80 Entrevista a P. Alabarces (MTU), 2015; Volante FAUDI (Filosofía y Letras), “¿Qué pasa en la facultad?", 1983.

81 La Nación, "Los estudiantes de Filosofía dejaron de pagar el arancel" julio de 1983; Tiempo Argentino, "Los estudiantes de Filosofía dejaron de pagar aranceles", 22/07/1983.

${ }^{82}$ Aquí y Ahora, "Movilización universitaria", n. 21, agosto de 1983.

${ }^{83}$ Aquí y Ahora, "Los universitarios dan el presente", n. 23, septiembre de 1983.

${ }^{84}$ Entrevista a A. González Escudero (Nexo-Revalúo), 2017.

85 Entrevistas a P. Alabarces (MTU), L. Luchilo, V. Cipolla, A. Delich (FM-JCN), Virginia Ferraro (sin militancia orgánica), P. Mauas (UJS), J.P. Paz (FJC), A. González Escudero (Nexo-Revalúo), realizadas por la autora entre 2015 y 2017.

${ }^{86}$ Sobre la heterogeneidad y complejidad de las actitudes sociales bajo regímenes autoritarios, véase Peukert (1987); Ludtke (1995), Passerini (2009). Sobre el caso argentino, los trabajos de Lvovich $(2009 ; 2010)$ y Águila $(2008 ; 2015)$ son una referencia destacada. Sobre la variedad de actitudes hacia le dictadura en las universidades argentinas, véase Rodríguez (2014), Luciani (2014) y Seia (2015).
} 


\section{"La educación es un derecho, no un privilegio": la lucha estudiantil contra el arancel universitario durante la última dictadura en Argentina (1980- 1983)}

sencillo. El pasaje del desacuerdo a la movilización colectiva no era ni directo ni inmediato. Encontramos líneas de acción no conformistas e incluso protestas de carácter anti-dictatorial que se funden con señales de resignación y adaptación en el marco de una universidad intervenida.

A pesar de dichas dificultades para desarrollar las medidas de protesta, cuando se concretaban las mismas lograban avances en su pelea contra el arancel al conseguir que no fueran exigidos los comprobantes de pago para el desarrollo de la vida académica y administrativa en las facultades. En la Facultad de Medicina, asimismo, la movilización estudiantil de más de cien asistentes convocada por el Centro de Estudiantes contra el cobro del arancel logró que el decanato se comprometiera a no exigir la chequera con los pagos al día para rendir los exámenes. Entre sus cánticos, la prensa destacaba: "Se va acabar, se va a acabar el arancel en la facultad" y "Yo quiero estudiar, sin arancel y sin policía en la universidad.". ${ }^{77}$ Comprobamos que, a medida que se acercaba el fin del gobierno de facto y ante la movilización estudiantil, las autoridades iban flexibilizando las exigencias respecto al arancel.

\section{A modo de cierre}

En el presente artículo hemos descripto el proceso de organización y movilización estudiantil contra el arancelamiento de los estudios de grado durante la última dictadura, particularmente, en la UBA. La lucha contra la imposición de cobro de tarifas para acceder y permanecer en el sistema de educación superior en tanto derecho garantizado por la Constitución Nacional se articuló rápidamente con la pelea contra el denominado "limitacionismo" de la política universitaria de la dictadura que no tenía otra finalidad que el achicamiento de las unidades académicas. Finalmente, estos cuestionamientos conformaron una crítica general al modelo universitario del "Proceso de Reorganización Nacional" y al régimen que había intentado imponerlo.

La movilización contra el arancel recurrió a un repertorio de acciones variado que incluyó desde el aprovechamiento de las "brechas institucionales" para impulsar el "no pago", la recolección de firmas en respaldo a petitorios para presentar ante las autoridades, concentraciones y recuperó la movilización callejera de la tradición histórica del movimiento estudiantil argentino. Asimismo, potenció el surgimiento de comisiones de estudiantes contra el mismo en el marco de los Centros y las Comisiones Reorganizadoras que desde los meses posteriores al golpe de estado se esforzaban para sostener su actividad a partir de la acción de los y las militantes de las agrupaciones radicales y de izquierda, ante la desarticulación de los grupos peronistas.

${ }^{87}$ La Nación, "Procuran un acuerdo programático para la FUBA", 04/08/1983; Clarín, "Protesta callejera de estudiantes de medicina", 06/08/1983. 


\section{Guadalupe Seia}

De este modo, hemos descripto, por un lado, la centralidad de la reivindicación contra el arancel en el proceso de rearticulación del movimiento estudiantil universitario de Buenos Aires. Por otro, que a nivel universitario los y las jóvenes formaron parte activa de agrupaciones, comisiones, centros y federaciones, incluso antes de la derrota en la Guerra de Malvinas o del proceso electoral a nivel nacional. El movimiento estudiantil, con sus dificultades y sus novedades, buscó seguir desarrollando sus actividades militantes, sosteniendo sus organizaciones y ocupándose de los principales problemas de la vida universitaria bajo la dictadura. Los límites en la imposición del proyecto autoritario en los claustros, y de sus superación en el marco de la transición democrática, no pueden ser comprendidos cabalmente si se soslaya el papel de esta actor que declararon muerto luego del golpe de estado.

Las críticas al modelo universitario anti-reformista, excluyente y elitista del autodenominado "Proceso de Reorganización Nacional", posibilitaron al movimiento estudiantil construir por oposición un modelo alternativo, el de la democracia, en el cual se volvía fundamental la garantía del derecho a la educación. Este fue justamente uno de los argumentos centrales que enarbolaban las agrupaciones estudiantiles para convocar al "no pago" del arancel y pedir su erradicación definitiva. Las limitaciones en el ingreso junto al conjunto de aranceles y el resto de los gastos involucrados en la realización de una carrera universitaria significaban trabas fundamentales para el respeto del derecho a la educación y la igualdad ante la ley de los ciudadanos argentinos.

En función de lo expuesto, consideramos fundamental recuperar el papel protagónico desplegado por el movimiento estudiantil, aún con dificultades y limitaciones para movilizar a la mayoría del alumnado, en la defensa y la reinstauración de la gratuidad de la educación superior en las universidades públicas. La derogación de la Ley $\mathrm{N}^{\circ} 22.207 / 80$ en 1984 no puede ser entendida sin la resistencia estudiantil contra dicha normativa en general y contra algunos de sus artículos, en particular, como el arancelamiento de la formación universitaria. De este modo, tampoco podemos explicar la expansión de la matrícula universitaria sin considerar el aporte clave de la militancia estudiantil en la construcción de una agenda universitaria que incluía el libre acceso y el fin del cobro de tarifas para desarrollar estudios superiores. En buena medida, ciertos principios fundamentales del sistema universitario de la etapa democrática son deudores de la incorporación al ideario colectivo sobre la educación pública de las banderas desplegadas por el movimiento estudiantil durante la última dictadura en Argentina. ${ }^{88}$

\footnotetext{
88 Sobre los rasgos del sistema universitario argentino durante la etapa democrática, véase Buchbinder y Marquina (2008) y Mendonça (2020), sobre los rasgos del movimiento estudiantil en esos años, consultar Millán y Seia (2019) y Cristal (2020). En este conjunto de textos se reflexiona acerca de los cambios institucionales y políticos a nivel universitario luego del final de la dictadura, atendiendo a las modalidades en que la agenda estudiantil construida en dictadura fue tramitada y también se fue actualizando ante nuevas realidades y problemáticas de un sistema masivo, heterogéneo y fragmentado.
} 
"La educación es un derecho, no un privilegio": la lucha estudiantil contra el arancel universitario durante la última dictadura en Argentina (19801983)

\section{Referencias Bibliográficas}

Águila, G. (2008). Dictadura, represión y sociedad en Rosario, 1976/1983. Un estudio sobre la represión y los comportamientos y actitudes sociales en dictadura, Buenos Aires: Prometeo.

Águila, G. (2015). "Violencia política, represión y actitudes sociales en la historia argentina reciente". En P. Folguera y J. Pereira, et al. (eds.). Pensar con la Historia desde el siglo XXI. XII Congreso de la Asociación de Historia Contemporánea. Madrid: UAM.

Beltrán, M. (2013). La Franja. De la experiencia universitaria al desafío del poder. Buenos Aires: Aguilar.

Benente, M. (Comp.) (2019). Donde antes estaba solamente admitido el oligarca: la gratuidad de la educación superior a 70 años. José C. Paz: Edunpaz.

Blanco, R. y Vommaro, P. (2018). Activismo juvenil en los años ochenta en Argentina. Dos generaciones políticas entre el partido y la universidad. Revista Latinoamericana de Ciencias Sociales, Niñez y Juventud, 16 (2).

Blanco, R. y Vommaro, P. (2017). "Otros caminos, otros destinos: transformaciones en los espacios y prácticas cotidianas de participación juvenil en los años ochenta". En M. Vázquez, et al. Militancias juveniles en la Argentina democrática. Buenos Aires: Imago Mundi.

Bonavena, P. y M. Millán (2008). Las luchas estudiantiles por el ingreso irrestricto al sistema Universitario en 1971. Ponencia presentada en IV Jornadas de Trabajo sobre Historia Reciente, Rosario.

Brunner, J. (1985). El movimiento estudiantil ha muerto. Nacen los movimientos estudiantiles. Material de discusión FLACSO (71).

Buchbinder, P. y M. Marquina (2008). Masividad, heterogeneidad y fragmentación: el sistema universitario argentino 1983-2008. Buenos Aires: UNGS/Biblioteca Nacional.

Califa, J. (2014). Reforma y revolución. La radicalización política del movimiento estudiantil de la UBA 1943-1966. Buenos Aires: EUDEBA.

Califa, J. y G. Seia (2017). La ampliación del sistema universitario argentino durante la "Revolución Argentina". Un estudio de sus causas a través del caso de la Universidad de Buenos Aires (1969-1973). A Contracorriente (1).

Califa, J. (2017). Dos FUAS en los años setenta. El movimiento estudiantil en las postrimerías de la Revolución Argentina. Anuario de la Escuela de Historia Virtual (12).

Cano, J. (1985). La educación Superior en la Argentina. Buenos Aires: FLACSO CRESALC - UNESCO. 


\section{Guadalupe Seia}

Casola, N. (2009). Política Obrera frente a la Dictadura Militar (1976-1983). Ponencia presentada en IX Encuentro Nacional y III Congreso Internacional de Historia Oral de la República Argentina, Buenos Aires.

Casola, N. (2015). El PC argentino y la dictadura militar. Militancia, estrategia política y represión estatal. Buenos Aires: Imago Mundi.

Cristal, Y. (2017). El movimiento estudiantil de la Universidad de Buenos Aires en el final de la última dictadura (1982-83), Sociohistórica (40).

Cristal, Y. (2020). El movimiento estudiantil de la UBA en democracia (1983-2001). (Tesis de Doctoral). UBA.

Cristal, Y. y Seia. G. (2018). La izquierda estudiantil de la Universidad de Buenos Aires en la transición democrática (1982-1985). Archivos de historia del movimiento obrero y la izquierda (12).

Dalmazzo, G. (1997). Línea recta: estudiantes en lucha. Todo es Historia (360).

Dip, N. 2017. Libros y Alpargatas. Las tramas discursivas y organizativas del proceso de peronización de estudiantes, docentes e intelectuales de la Universidad de Buenos Aires 1966-1974. Rosario: Prohistoria.

Franco, M. (2018). El final del silencio, Dictadura, sociedad y derechos humanos en la transición (Argentina, 1979-1983). Buenos Aires: FCE.

Friedemann, S. (2019). "Historia de la gratuidad y el ingreso irrestricto en la universidad argentina. El caso de la Universidad Nacional y Popular de Buenos Aires (1973-1974)". En M. Benente, op. cit.

Gilbert, I. (2009). La FEDE. Alistándose para la revolución. La Federación Juvenil Comunista 1921-2005. Buenos Aires: Sudamericana.

Gillespie, R. (1987). Soldados de Perón. Los montoneros. Buenos Aires: Grijalbo.

Gómez, A. (1995). No nos han vencido... Historia del Centro de Estudiantes de Derecho-UBA. Buenos Aires: EUDEBA.

Larrondo, M. y Cozachcow, A. (2017). “Un llamado a la unidad: la experiencia del Movimiento de Juventudes Políticas (MOJUPO) en la transición a la democracia”. En M. Vázquez, et al., op. cit.

Levenberg, R. y Merolla, D. (1988). Un solo grito. Crónica del movimiento estudiantil universitario de 1918 a 1988. Buenos Aires: FUBA.

Luciani, L. (2014). La Universidad Nacional de Rosario durante la última dictadura militar argentina (1976-1983). Un acercamiento a los conflictos al interior de la gestión interventora. Revista Binacional Brasil-Argentina (3-1).

Ludtke, A. (1995). De los héroes de la resistencia a los coautores. Ayer (19). 
"La educación es un derecho, no un privilegio": la lucha estudiantil contra el arancel universitario durante la última dictadura en Argentina (19801983)

Lvovich, D. (2009). Sistema político y actitudes sociales en la legitimación de la dictadura militar argentina (1976-1983). Ayer (75).

Lvovich, D. (2010). "Actitudes sociales durante la dictadura militar argentina: las organizaciones sociales y el diálogo político de 1980". En E. Bohoslavsky, et al. Problemas de historia reciente del Cono Sur. Buenos Aires: Prometeo/UNGS.

Manzano, V. (2018). "Por una universidad agradable y eficiente": las agrupaciones estudiantiles liberales en la década de 1980". En D. Mauro y J. Zanca. La reforma universitaria cuestionada. Rosario: HyA ediciones.

Mason, T. (2007). La oposición obrera en la Alemania Nazi. Taller(24).

Mendonça, M. (2017). Entre botas y votos. Las políticas universitarias durante la "Revolución Argentina". Del golpe de Estado de 1966 a las elecciones de 1973 (Tesis Doctoral Inédita). IDES-UNGS, Los Polvorines.

Mendonça, M. (2020). Apuntes sobre estadísticas de la universidad pública argentina: construcción de series de matrícula, ingresos y egresos, y observaciones sobre su evolución en las últimas cinco décadas, Revista de Estudios Teóricos y Epistemológicos en Política Educativa (5).

Millán, M. (2016). La Juventud Universitaria Peronista en las memorias de la militancia estudiantil reformista y marxista de la UBA, 1973-1976. Historia, Voces y Memoria (10).

Millán, M (2018). En las últimas casamatas. El movimiento estudiantil de la UBA en 1975. Estudios (40).

Millán, M y Seia, G. (2019). El movimiento estudiantil como sujeto de conflicto social en Argentina (1871-2019). Apuntes para una mirada de larga duración. Entramados y Perspectivas (9).

Osuna, F. (2015). De la Revolución socialista a la Revolución democrática. Las prácticas del Partido Socialista de los Trabajadores/Movimiento al Socialismo durante la última dictadura (1976-1983). La Plata-Posadas: UNLP-UNAM.

Passerini, L. (2009) [1987]. Fascism in Popular Memory. The cultural experience of the Turin working class. Cambridge: Cambridge University Pres.

Peukert, D. (1987) [1982]. Inside the Nazi Germany. Conformity, Opposition, and Racism in Everyday Life. New Haven-London: Yale University Pres.

Pis Diez, N. (2018). Peronismo, universidad y oposición reformista. El caso de la ciudad de La Plata/Ciudad Eva Perón (1943-1955). Estudios sociales (54).

Pis Diez, N. (2019). La supresión del cobro de aranceles universitarios en Argentina (1949/1952/1954). Posiciones y oposiciones en torno a una pieza clave del "modelo peronista de universidad". En M. Benente, op. cit. 


\section{Guadalupe Seia}

Polak, L. y J. Gorbier (1994). El movimiento estudiantil Argentino (Franja Morada 1976-1986). Buenos Aires: CEAL.

Risler, J. (2018). La acción psicológica: dictadura, inteligencia y gobierno de las emociones (1955-1981). Buenos Aires: Tinta Limón.

Rodríguez, L. (2014). La universidad argentina durante la última dictadura: actitudes y trayectorias de los rectores civiles (1976-1983). Revista Binacional Brasil-Argentina (3-1).

Rodríguez, L. (2015). Universidad, peronismo y dictadura. 1973-1983. Buenos Aires: Prometeo.

Saadi, M. (2004). La resistencia después del final. Buenos Aires: Nuevos tiempos.

Saraniti, M. (2018). "La Federación Juvenil Comunista frente al "Proceso de Reorganización Nacional": la construcción de un discurso legitimador del régimen". En F. Levin (comp.). Tramas del pasado reciente argentino: historia, memoria y transmisión. Los Polvorines: UNGS.

Seia, G. (2014). La lucha del Movimiento Estudiantil por el ingreso directo: una aproximación al caso de la Universidad de Buenos Aires entre 1969 y 1973. En M. Millán. Universidad, política y movimiento estudiantil en Argentina, entre la "Revolución Libertadora" y la democracia del '83. Buenos Aires: Final Abierto.

Seia, G. (2015). Reconfiguraciones de la vida estudiantil durante la última dictadura. Apuntes sobre los casos de las Facultades de Filosofía y Letras y Ciencias Exactas y Naturales de la Universidad de Buenos Aires (1976-1981). Revista Binacional Brasil-Argentina (4-1).

Seia, G. (2016): “La Universidad de Buenos Aires UBA entre la «misión Ivanissevich» y la la vida estudiantil” (Tesis de Maestría inédita). Los Polvorines: UNGS.

Seia, G. (2017). La búsqueda por la institucionalización y "normalización universitaria" de la última dictadura en Argentina. Ley universitaria, nuevo estatuto y concursos docentes en el caso de la Universidad de Buenos Aires (1980-1983). Debate Universitario (10).

Seia, G. (2018a). La aplicación de la política de "re-dimensionamiento" en la Universidad de Buenos Aires (UBA) durante la última dictadura (1976-1983). Revista Iberoamericana de Educación Superior (25).

Seia, G. (2018b). La dictadura contra la Reforma Universitaria. Orientación de la política universitaria en la Universidad de Buenos Aires (1976-1983). Revista Historia de la Educación Latinoamericana (30).

Seia, G. (2019a). De la revolución a la reforma. Reconfiguraciones de las formas de militancia estudiantil en la Universidad de Buenos Aires entre 1976 y 1983 (Tesis Doctoral Inédita). UBA, Buenos Aires. 
"La educación es un derecho, no un privilegio": la lucha estudiantil contra el arancel universitario durante la última dictadura en Argentina (19801983)

Seia, G. (2019b). Represión, control y disciplinamiento en la Universidad de Buenos Aires durante la última dictadura (1976-1983). Universidades (80).

Seia, G. (2019c). La "depuración universitaria" como efecto del plan represivo durante la última dictadura. Una caracterización general sobre el caso de la Universidad de Buenos Aires entre 1976 y 1983. Ponencia presentada en III Coloquio Internacional sobre Violencia Política en el Siglo XX y IV Jornadas de Trabajo de la Red de Estudios sobre Represión y Violencia Política (RER). Rosario.

Toer, M. (1988). El movimiento estudiantil de Perón a Alfonsín. Buenos Aires: CEAL.

Vila, P. (1985). Rock nacional: crónicas de la resistencia juvenil. En E. Jelin. Los nuevos movimientos sociales/1. Buenos Aires: CEAL.

\section{Fuentes}

Conferencia Regional de Educación Superior para América Latina y el Caribe, "III Conferencia Regional de Educación Superior para América Latina y el Caribe", Córdoba, 2018.

Diarios La Voz, Clarín, Tiempo Argentino, La Nación, Buenos Aires, 1982-1983. Recortes seleccionados y agrupados por la Secretaria de Prensa de la UBA. ${ }^{89}$

Partido Comunista Revolucionario (PCR), Informe Universitario, Buenos Aires, 1981.

Partido Socialista de los Trabajadores (PST), Informes Universitarios, Buenos Aires, 1981-1983.

Revista Aquí y Ahora, órgano de comunicación de la Federación Juvenil Comunista (FJC-PC), Buenos Aires, 1981-1982.

Revista Criterio, n. 1799, Buenos Aires, 1979.

Hoja Estudiantil (PST), "Presentar las exenciones, un primer paso para no pagar el arancel”, n. 1, Buenos Aires, 1981.

Revista Imagen, órgano de comunicación de la FJC-PC, Buenos Aires, 1977-1981.

Revista Nueva Generación, órgano de comunicación de la Unión de Juventudes por el Socialismo (UJS-PO), Buenos Aires, 1977-1981.

Revista Nueva Juventud, órgano de comunicación de la Juventud Comunista Revolucionaria (JCR-PCR), Buenos Aires, 1976-1982.

${ }^{89}$ Por este motivo no disponemos de los números de página de los artículos citados en dichos diarios. 


\section{Guadalupe Seia}

Revista Opción, órgano de comunicación de la Juventud del PST, Buenos Aires, 19781982.

Secretaría de Derechos Humanos de la Nación, Informe del Registro Unificado de Víctimas del Terrorismo de Estado (RUVTE), 2018.

Secretaría de Políticas Universitarias del Ministerio de Educación de la Nación, Series estadísticas, 2015.

Universidad de Buenos Aires, Resoluciones rectorales, 1976-1983.

Universidad de Buenos Aires, Series Estadísticas $\mathrm{N}^{\circ}$ 5. Disponible en: http://www.uba.ar/institucional/censos/series/default.htm [Última consulta: 16/10/2019]

Volantes, informes y plataformas estudiantiles UBA, Buenos Aires, 1976-1983.

\section{Testimonios}

Entrevistas a Andrés Delich, Víctor Cipolla, Lucas Luchilo, Federico Storani y José Demichelis (militantes de la Franja Morada); Pablo Alabarces (militante del Movimiento de Transformación Universitaria); Juan Pablo Paz y Patricio Geli (militantes de la Federación Juvenil Comunista); Pablo Mauas y Daniel Sierra (militantes de la Unión de Juventudes por el Socialismo); y Virginia Ferraro, realizadas por G. Seia durante 2015.

Entrevistas a Claudia y Sergio (militantes de la juventud del Partido Socialista de los Trabajadores), Alejandro González Escudero (militante de Nexo-Revalúo), Irma Medina (militante de la Juventud Universitaria Peronista), Ileana Celotto y Hernán Díaz(militantes de la Unión de Juventudes por el Socialismo); Marcelo Buckley (militante de la Franja Morada), realizadas por G. Seia durante 2017.

Recibido: 04/01/2020

Evaluado: $15 / 02 / 2020$

Versión Final: 24/03/2020 